\title{
Treatment of Wastewater Containing Organic Dyes: Recovery of Dye Adsorbed on Starch- Based Materials Through Conversion of Adsorbent into Alcohol
}

\author{
Sati Saha, M. Yousuf Ali Mollah, Md. Abu Bin Hasan Susan and Md. Mominul Islam* \\ Department of Chemistry, Dhaka University, Dhaka-1000, Bangladesh \\ (Received: 14 January 2015; Accepted: 17 February 2015)
}

\begin{abstract}
The recovery of a cationic dye, methylene blue (MB), from the residue generated during its removal via adsorption on starch-based adsorbents from aqueous solution was studied. Adsorption characteristics of MB on wheat flour (WF) and pure starch were analyzed using UV-visible spectroscopy. WF and starch were loaded with an optimum amount of MB producing MB-WF and MB-starch, respectively, leaving residues. The desorption characteristics and \% recovery of MB from both the synthetic wastes were determined. The effects of yeast and temperature on the recovery of MB were also investigated. The mechanism of desorption of MB from the surface of starch was established by analyzing the weight loss profiles for different mixtures containing water, MB, WF or starch and yeast. Finally, the MB-WF and MB-starch species were fermented using diastase enzyme and yeast and the products formed were characterized by chemical, UVvisible spectroscopic and gas chromatographic analyses. The fermentation process was found to successfully convert starch to ethanol without decolorizing the MB species present in the residue.
\end{abstract}

Keywords: Starch, Methylene blue, Adsorption, Recovery, Fermentation

\section{Introduction}

Modern civilization relies to a significant extent on textile, paper, plastics, leather, cosmetics and dyeing industries. It has been reported that in a particular dyeing process $10-15 \%$ of dyestuff is generally lost directly to the effluent ${ }^{1-3}$. The discharged dyestuff causes potential danger to bioaccumulation $^{2}$. Therefore, design of an effluent treatment plant that can effectively clean industrial effluents without leaving any fragments of dye species and generating secondary wastes during its operation has been one of the prime challenges to the scientific community.

Several methods, for example, adsorption, coagulation, flocculation, chemical oxidation, membrane filtration, and biological and electrochemical treatments have been developed for treatment of water containing dyes ${ }^{1-10}$. Recently, we have investigated the catalytic electrochemical treatment of wastewater containing methylene blue (MB) as an alternative approach to the advanced oxidation process with Fenton reagent ${ }^{3}$. However, the adsorption has been proved to be an effective and attractive method since it can remove dye species completely without leaving any fragment in the effluent.

Removal of dyes using starch-based adsorbents has been reported earlier ${ }^{11-16}$. Zheng et al. ${ }^{14}$ examined adsorption of MB from aqueous solution through ultra-filtration and reported the possibility of its recovery. The adsorptiondesorption characteristics of reactive $\mathrm{X}-3 \mathrm{~B}$ red dye on Chinese typical soils such as paddy soil, red soil, brown earth and drab soil were reported ${ }^{12}$. Zargar et al. ${ }^{13}$ studied the removal and recovery of $\mathrm{MB}$ by activated carbon modified with iron oxide nanoparticles. Robinson et al. ${ }^{11}$ used agricultural residues to remove dyes such as cibacron red, cibacron blue, cibacron yellow, remazol red and remazol black from aqueous solution. However, to the best of our knowledge, suitable adsorbent that can be recycled through the recovery of dyes or can be converted into some useful products (e.g., alcohol) have not been reported in the literature.

\footnotetext{
* Author for correspondence. e-mail:mominul@du.ac.bd
}

In this study, we focused on the recovery of MB from the $\mathrm{MB}$ adsorbed on wheat flour (WF) (MB-WF) and starch MB-starch residues by natural decomposition and fermentation of adsorbents. The adsorption-desorption profiles of MB on both starch and WF were studied. The recovery of MB was carried out from MB-WF and MB-starch in deionized water in the absence and the presence of yeast. A route of desorption of MB from the starch-based adsorbents is proposed. An attempt has been successfully made to convert starch present in the MB-WF residue into alcohol through fermentation without degradation of MB species.

\section{Materials and Methods}

Materials and chemicals

Analytical grade MB was received from Sigma-Aldrich (Germany). Food grade wheat flour (WF) was collected from local market (ACI, Bangladesh). Starch and diastase enzyme were obtained from Merck (Germany). Yeast extract was purchased from Techno Pharmachem, Haryana (India). All chemicals were used without further purifications. The solutions were prepared using deionized water (specific conductance $<0.1 \mu \mathrm{S} \mathrm{cm} \mathrm{cm}^{-1}$ ) prepared with BOECO pure (Model-BOE 8082060, Germany). Stock solution of $\mathrm{MB}$ was prepared by dissolving the solid dye in de-ionized water and the solution was kept in dark.

$U V$-visible spectral analysis and determination of concentration of $M B$

Visible spectrum of aqueous solution of MB was recorded using a double beam UV-visible spectropho-tometer (UV1650A, Shimadzu, Japan) and the characteristic absorption maximum $\left(\lambda_{\max }\right)$ was found at $664 \mathrm{~nm}\left(\varepsilon=74164 \mathrm{~L} \mathrm{~mol}^{-1}\right.$ $\mathrm{cm}^{-1}$ ). The amount of MB (in g) was calculated from the concentration of $\mathrm{MB}$ determined using Beer-Lambert law and formula weight of MB (320 $\left.\mathrm{g} \mathrm{mol}^{-1}\right)$.

Adsorption study and preparation of $M B-W F$ and $M B-$ starch residues

Adsorptions of MB on WF and starch were carried out in a $200.0 \mathrm{~mL}$ beaker at $25{ }^{\circ} \mathrm{C}$. In a typical measurement, $2.5 \mathrm{~g}$ of WF or starch was mixed with about $10.0 \mathrm{~mL}$ deionized 
water and allowed to stand for $30 \mathrm{~min}$ for complete soaking/swelling. The supernatant water was filtered out and $100.0 \mathrm{~mL}$ of $4.0 \times 10^{-6} \mathrm{M}$ MB solution was added to the pretreated WF or starch kept in the beaker and the mixture was stirred gently from time to time. At predetermined time intervals, $3.0 \mathrm{~mL}$ aliquot solution was transferred and centrifuged for at least $10 \mathrm{~min}$. The clear solution was used for spectral analysis and after measurements the used solution was quantitatively transferred to the beaker. The amount of adsorbed $\mathrm{MB}\left(W_{\mathrm{ad}}\right)$ was estimated using:

$$
W_{\mathrm{ad}}=\frac{\left(C_{1}-C_{2}\right) \times M}{1000 \times \mathrm{m}} \times V_{\mathrm{ad}}
$$

where $C_{1}$ and $C_{2}$ represent the initial concentration and concentration at a definite time interval of $\mathrm{MB}$, respectively, $M$ is the formula weight of $\mathrm{MB}, V_{\text {ad }}$ is the total volume of solution used, $m$ is the amount of adsorbent in $\mathrm{g}$.

MB-WF and MB-starch residues were prepared by aging 2.5 $\mathrm{g}$ of pre-soaked WF and starch, respectively, in a beaker containing $100.0 \mathrm{~mL}$ of $4.0 \times 10^{-6} \mathrm{M} \mathrm{MB}$ solution for $24 \mathrm{~h}$. The solutions were filtered out and the dye-adsorbed residues (MB-WF and MB-starch) were washed with sufficient amount of deionized water to remove any free $\mathrm{MB}$ species. The residue was then carefully transferred to a special cell having screw cap for desorption study (vide infra).

\section{Desorption study and \% recovery of $M B$}

$50.0 \mathrm{~mL}$ distilled water was added to the water-soaked MBWF or MB-starch residue kept in a screw cap sealed cell for desorption study. When required, $0.5 \mathrm{~g}$ yeast was added to it. The cell was then kept in the incubator maintaining the temperatures of 25 and $37{ }^{\circ} \mathrm{C}$. At different time intervals, 3.0 $\mathrm{mL}$ aliquot supernatant solution was transferred to a centrifuge tube and centrifuged for $10 \mathrm{~min}$. The clear solution was then used for determination of the concentration of $\mathrm{MB}$ as in the case of adsorption study. The amount of MB desorbed $\left(W_{\text {de }}\right)$ was determined using (Eq. 2):

$$
W_{\mathrm{de}}=\frac{C \times M}{1000 \times m} \times V_{\mathrm{de}}
$$

where, $C$ represents the concentration of $\mathrm{MB}$ in the supernatant solution, and $V_{\text {de }}$ is the total volume of solution used for desorption study.

The \% recovery of MB was determined from the amount of MB adsorbed $\left(W_{\mathrm{ad}}\right)$ during the formation of a particular residue (estimated using Eq. 1) and the amount of $\mathrm{MB}$ desorbed $\left(W_{\mathrm{de}}\right)$ from the same residue by:

$$
\% \text { Recovery }=\frac{\left(W_{\mathrm{ad}}-W_{\mathrm{de}}\right) \times 100}{W_{\mathrm{ad}}}
$$

Study of weight loss during recovery of $M B$

For the study of weight loss, six $20 \mathrm{~mL}$ identical vials provided with screw caps were used. A hole of $1.5 \mathrm{~mm}$ diameter was made on the cap of each vial to allow any volatile materials to escape from the vial. The vials were charged with $5.0 \mathrm{~mL}$ of $4.0 \times 10^{-6} \mathrm{M}$ MB solution and 5.0 $\mathrm{mL}$ of water and different amounts of yeast, WF or starch (Table 1). The vials were kept open in air at ambient temperature of ca. $25{ }^{\circ} \mathrm{C}$. The masses of vials were recorded before and after filling. The percentage of weight loss (\% $W_{\text {loss }}$ ) at different time intervals were determined using:

$$
\% W_{\text {loss }}=\frac{\left(w_{0}-W_{1}\right)}{W_{0}} \times 100
$$

where, $w_{0}$ and $w_{1}$ represent the initial weight of the vial containing all masses and weight of the vial after certain time intervals, respectively.

\section{Fermentation of $M B-W F$ residue}

For the study of conversion of starch into ethanol, typically $10.0 \mathrm{~g}$ residue of MB-WF or MB-starch was taken in a beaker. $1.0 \mathrm{~g}$ diastase enzyme was added and the mixture was kept at $55{ }^{\circ} \mathrm{C}$ for $2 \mathrm{~h}$. The slurry was then cooled and $1.0 \mathrm{~g}$ yeast extract was added to the slurry. The obtained mass was transferred to a cell sealed with a screw cap and kept at $37{ }^{\circ} \mathrm{C}$ in an incubator for $72 \mathrm{~h}^{17}$. The products were analyzed by chemical, gas chromatographic (GC) (Model: Clarus 500, PerkinElmer, USA) and spectroscopic methods.

\section{Results and Discussion}

\section{Study of adsorption of MB on WF and starch}

Fig. 1 represents the profiles for adsorption of MB on WF and starch. The amount of MB adsorbed on WF increases with time up to $20 \mathrm{~h}$ and then gradually decreases. Similar trend was also observed for starch. However, time required for maximum adsorption of $\mathrm{MB}$ on starch was relatively shorter ( 5 h) than that with WF. The time may be considered as the time necessary to attain equilibrium for the adsorptions of MB. At equilibrium, the maximum adsorption of $\mathrm{MB}$ on starch was found to be higher than that on WF. Cheng et al. ${ }^{18}$ suggested that the adsorption of acid green 25 onto ethylenediamine modified starch depends on electrostatic attraction and hydrogen bonding. In this study, the adsorption of $\mathrm{MB}$ on WF and starch is considered to take place via hydrogen bonding between hydrophilic functional group of $\mathrm{MB}\left(\mathrm{CH}_{3}-\mathrm{N}^{+}-\mathrm{CH}_{3}\right)$ and $-\mathrm{OH}$ group of starch and the electrostatic forces between charged functional sites of adsorbents and MB. The active sites (surface area) for the adsorption of MB on WF would naturally be lower than that for pure starch, resulting in low

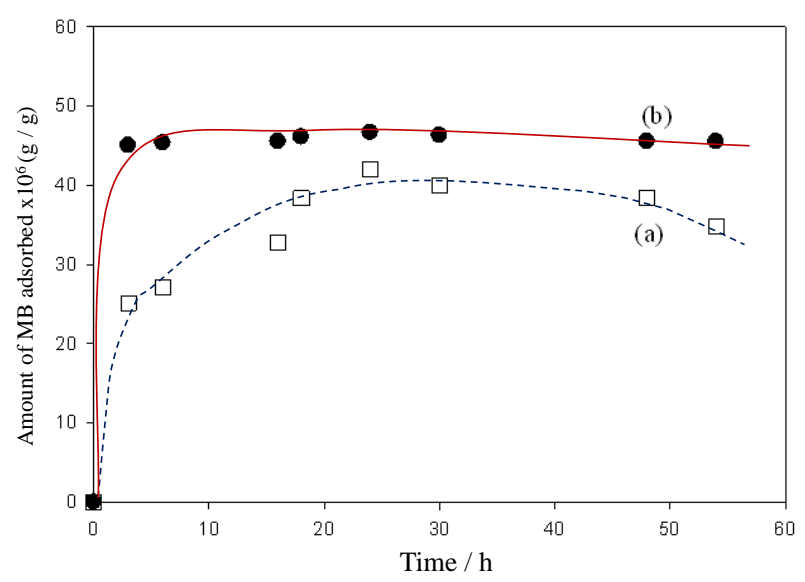

Fig. 1. Adsorption profiles of MB on (a) WF and (b) starch measured in aqueous suspension ( $\mathrm{pH}$ 6.8). 
extent of adsorption of MB since WF contains $73 \%$ starch, $14 \%$ protein and other ingredients ${ }^{17}$. The residues generated for the adsorption of MB on WF and starch were considered for the recovery of dye.

\section{Desorption of MB adsorbed on WF and starch}

Desorption profiles of MB from MB-WF and MB-starch species studied in the presence of yeast at $37^{\circ} \mathrm{C}$ is represented in Fig. 2. The amount of $\mathrm{MB}$ in aqueous system increases with time up to a certain limit after which the amount desorbed remains almost constant. A decrease in the amount of MB desorbed from MB-starch residue was also obtained after $30 \mathrm{~h}$. Similar results were obtained at $25{ }^{\circ} \mathrm{C}$ without addition of yeast (data not shown). Generally, the degree of desorption depends on temperature, presence of yeast and residues used (vide infra). However, the maximum amount of MB desorbed was found to be $4.14 \times$ $10^{-5}$ and $4.65 \times 10^{-5} \mathrm{~g}$ from per gram of MB-WF (at $72 \mathrm{~h}$ ) and MB-starch $(24 \mathrm{~h})$ residues, respectively. This is consistent since the amount of $\mathrm{MB}$ species in MB-WF residue is lower than that in MB-starch residue (Fig. 1). It is well-known that the starch-based materials undergo natural degradation by the action of bacteria and the degree of natural degradation depends on temperature ${ }^{19}$. The observed decrease in the amount desorbed from MB-starch after $30 \mathrm{~h}$ may result from the decomposition of $\mathrm{MB}$ in the presence of yeast (vide infra).

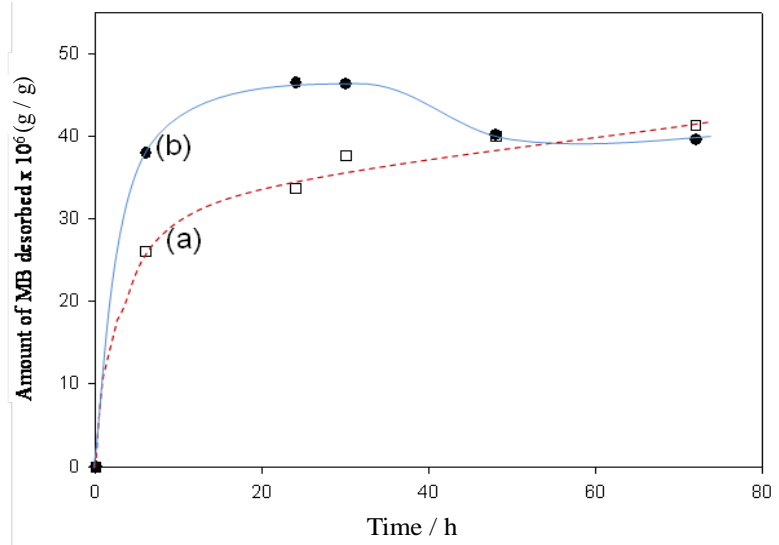

Fig. 2. Desorption profiles of MB from (a) MB-WF and (b) MBstarch species in the presence of yeast at $37{ }^{\circ} \mathrm{C}$ in aqueous solution (pH 6.8).

The desorbed MB in aqueous solution was characterized by spectral analysis (Fig. 3). The visible spectrum of desorbed MB shows characteristic absorption band as observed for a fresh solution of $\mathrm{MB}$ except for the shoulder at low wavelength range. The shoulder is possibly due to the presence of yeast in the solution. Both residues become colorless after desorption of $\mathrm{MB}$, whereas the solution shows marked increase in intensity of blue color with time. This is interesting, because it was likely that MB could readsorb on active surface of WF or starch. The surfaces of WF and starch might have been modified by microorganisms that catalyze desorption of $\mathrm{MB}$ to ultimately restrict re-adsorption of $\mathrm{MB}$ present in the solution. Most importantly, the MB species remains chemically unchanged during its adsorption and desorption even by the action of yeast.

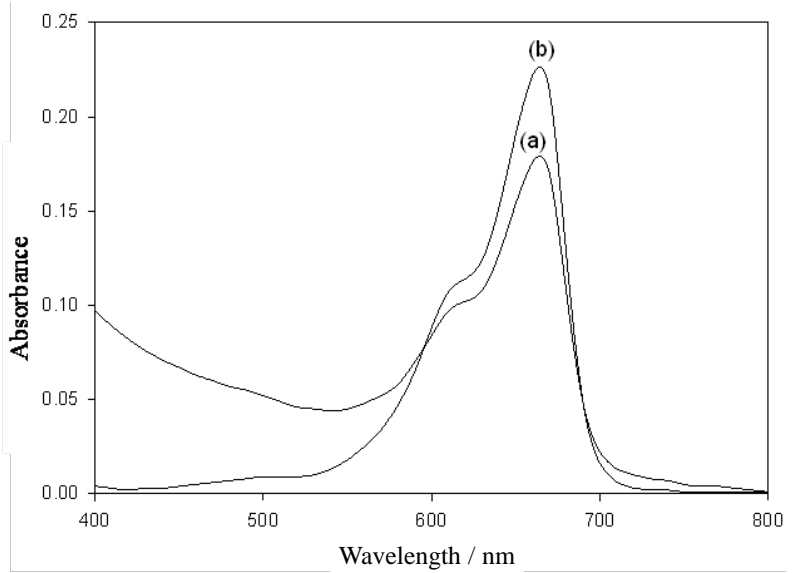

Fig. 3. Visible spectra of (a) $4.0 \times 10^{-6} \mathrm{M} \mathrm{MB}$ aqueous solution and (b) MB solution obtained after the desorption of $\mathrm{MB}$ from MB-WF species in the presence of yeast at $37^{\circ} \mathrm{C}$.

\section{Effects of yeast and temperature on the recovery of $M B$}

Fig. 4 illustrates the effects of yeast and temperature on the recovery of $\mathrm{MB}$ from MB-WF (A) and MB-starch (B) species. In the presence of yeast, a maximum recovery of 98.4\% of MB was achieved from MB-WF residue at $37^{\circ} \mathrm{C}$ (curve d, Fig. 4A), while 99.8\% MB was recovered from MB-starch residue under identical experimental conditions (curve d, Fig. 4B). Thus, the time required for maximum recovery from $\mathrm{MB}$-starch residue is about three-times lower than that from MB-WF residue. It may be noted that in case
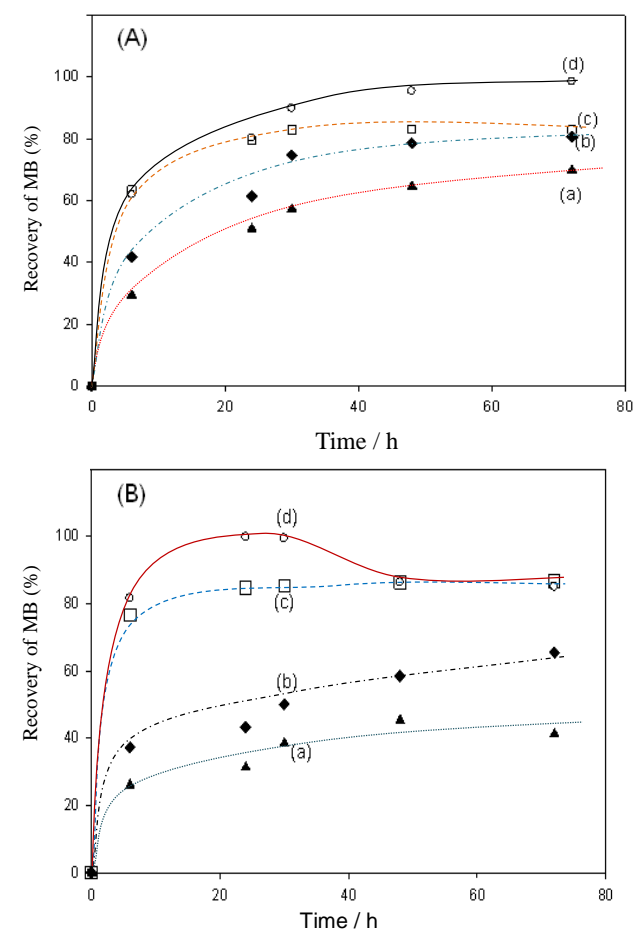

Fig. 4. Profiles of recovery of MB from MB-WF (A) and MBstarch (B) species in the absence $(a, b)$ and the presence (c,d) of yeast determined at $25{ }^{\circ} \mathrm{C}(\mathrm{a}, \mathrm{c})$ and $37{ }^{\circ} \mathrm{C}(\mathrm{b}, \mathrm{d})$ in aqueous suspension ( $\mathrm{pH}$ 6.8). 
of MB-starch residue, the \% recovery decreases with time (vide infra). The effect of yeast on the recovery of MB thus becomes apparent. For instance, the time required for $50 \%$ recovery of $\mathrm{MB}$ from $\mathrm{MB}-\mathrm{WF}$ and $\mathrm{MB}$-starch species was 10 and $24 \mathrm{~h}$, respectively, without and with yeast at $25^{\circ} \mathrm{C}$. The results at $37{ }^{\circ} \mathrm{C}$ indeed show similar features. Therefore, although the recovery of MB from both residues is feasible without the use of yeast, catalytic role is played by yeast for faster recovery of MB.

Table 1. Rate of weight loss of different samples studied for the recovery of $\mathrm{MB}$

\begin{tabular}{llcc}
\hline Sample & Composition & $\begin{array}{c}\text { Rate of weight loss } \\
\text { / (mg/h) }\end{array}$ & $R^{2}$ \\
\hline S1 & MB + Water & 1.0 & 0.9759 \\
S2 & MB + Yeast + Water & 0.9 & 0.9942 \\
S3 & MB + WF + Water & 4.4 & 0.9857 \\
S4 & MB + Yeast + WF + Water & 5.3 & 0.9993 \\
S5 & MB + Starch + Water & 1.2 & 0.9941 \\
S6 & MB+Yeast+Starch+Water & 1.3 & 0.9335 \\
\hline
\end{tabular}

In addition, temperature plays a crucial role in lowering the period as well as the percentage of maximum recovery of MB (Fig. 4). For MB-starch residue, about $60 \% \mathrm{MB}$ was recovered after $40 \mathrm{~h}$ at $25^{\circ} \mathrm{C}$, whereas this was increased to about $70 \%$ by raising the temperature to $37{ }^{\circ} \mathrm{C}$ (compare curves $\mathrm{a}$ and $\mathrm{c}$ in Fig. 4A). Similar observations are expected in the case of WF-MB residue. Cheng et al. ${ }^{18}$ studied desorption from adsorbed ethylenediamine-starch residue and reported that desorption can be enhanced by using sodium sulfate as an additive in aqueous solution. Zhou et al. ${ }^{12}$ reported that the amount of dye desorbed from soils increases gradually with increasing temperature. Physical adsorption that induces a low degree of adsorption is likely to result in a large \% recovery of $\mathrm{MB}$ at high temperature as in the present case.

On the other hand, yeast would result in a higher rate of conversion/degradation of starch or protein present on the surfaces of WF or starch particles, resulting in a faster desorption of MB. The observed maximum desorption at 37 ${ }^{\circ} \mathrm{C}$ corresponds to the optimum activity of yeast ${ }^{17}$ at this temperature. The \% recovery of $\mathrm{MB}$ from MB-WF and MBstarch residues may be compared here. At $25{ }^{\circ} \mathrm{C}$ and in the absence of yeast, 63 and $40 \%$ recovery of MB could be achieved from MB-WF and MB-starch residues, respectively, after $72 \mathrm{~h}$. The recovery of MB from MB-WF residue may be considered as economically viable since WF material is cheap and preferred for the removal and recovery of MB.

\section{Recovery of MB and formation of ethanol}

Starch is made from strings of 200 to 20,000 glucose units and is biodegradable in a wide variety of environments. It can be hydrolyzed into glucose by microorganism or enzymes as shown by Eqs. (5) and (6), and subsequent metabolized into $\mathrm{CO}_{2}$ and water ${ }^{20}$. Moreover, the yeast species converts carbohydrates into $\mathrm{CO}_{2}$ and alcohols by fermentation ${ }^{21-24}$. Secretion of zymase enzyme from yeast brings about conversion of glucose into ethanol and $\mathrm{CO}_{2}$
(Eq. 7$)^{25}$. In fact, during recovery of $\mathrm{MB}$, we observed bubbles due to the evolution of $\mathrm{CO}_{2}$ gas from the reaction system.

$$
\begin{array}{ll}
\left(\mathrm{C}_{6} \mathrm{H}_{10} \mathrm{O}_{5}\right)_{n}+\mathrm{nH}_{2} \mathrm{O} \underset{\text { maltose }}{\stackrel{\text { diastase }}{\longrightarrow}} & \mathrm{nC}_{12} \mathrm{H}_{22} \mathrm{O}_{11} \\
\mathrm{C}_{12} \mathrm{H}_{22} \mathrm{O}_{11}+\mathrm{nH}_{2} \mathrm{O} \stackrel{\mathrm{C}_{6} \mathrm{H}_{12} \mathrm{O}_{6}}{\longrightarrow} \\
\mathrm{C}_{6} \mathrm{H}_{12} \mathrm{O}_{6}+\text { zymase (yeast) } \longrightarrow 2 \mathrm{C}_{2} \mathrm{H}_{5} \mathrm{OH}+2 \mathrm{CO}_{2}
\end{array}
$$

Dyes usually undergo biodegradation in presence of microorganisms ${ }^{26}$. However, to better understand the mechanisms of recovery of MB from MB-WF and MBstarch residues, the weight loss of the masses used for the recovery of $\mathrm{MB}$ were analyzed. Although the \% weight loss for the samples at different time intervals for starch showed only a small variation, a significant variation in the \% weight loss could be marked for WF (Fig. 5). The rates of weight loss determined (Table 1) from the slopes of the weight loss vs. time profiles (Fig. 5) also provided useful information. The rates of weight loss for the samples without WF or starch (S1 and S2) are almost same.
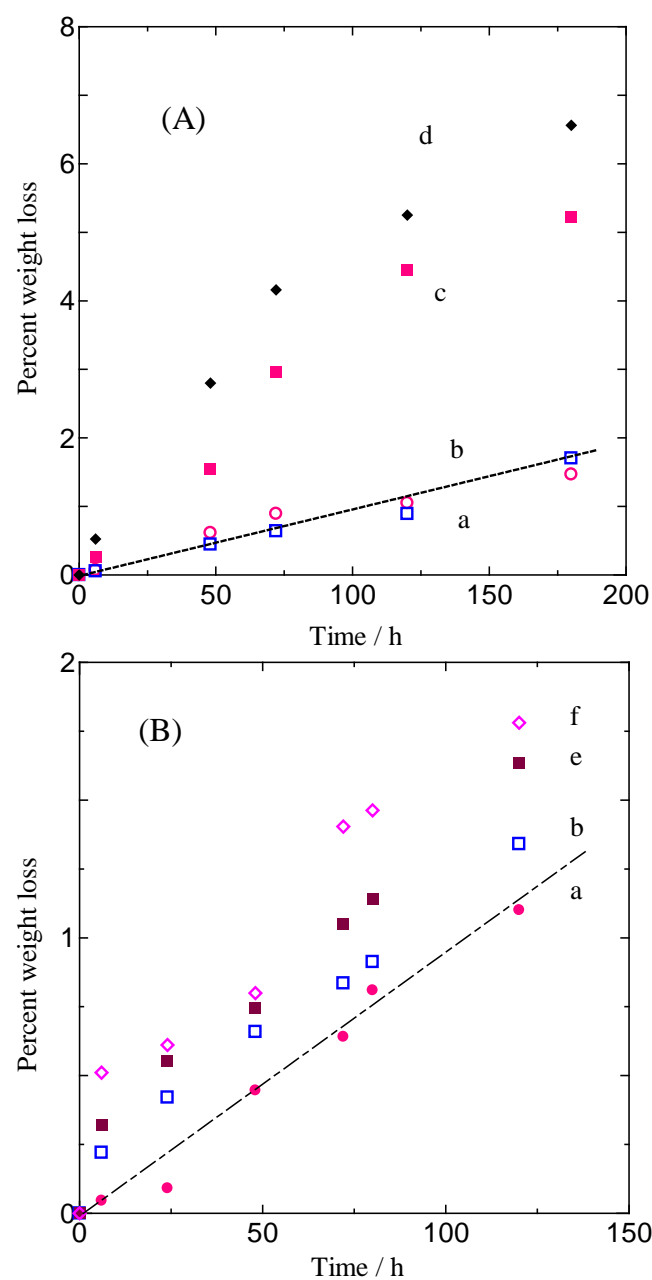

Fig. 5. Weight loss of different mixtures versus time profiles determined for the systems containing different materials. Panel (A) and (B) are for WF and starch, respectively. In both panels, the plots (a), (b), (c), (d), (e) and (f) represent the results for the samples S1, S2, S3, S4, S5 and S6, respectively (see Table 1). Broken lines are drawn for guiding the eyes. 
Similarly, the rates of weight loss of the samples with starch (S5 and S6) did not differ much. However, the values obtained in the presence of starch with or without yeast have been found to be slightly higher than the corresponding values in the absence of starch. The observed weight loss may thus be attributed to the natural evaporation of water, which does not change significantly due to the presence of yeast. The faster weight loss in presence of starch may be attributed to the consumption of starch to form ethanol and $\mathrm{CO}_{2}$ gas, to enhance the weight loss. Interestingly, the rates of weight loss for the samples with WF (S3 and S4) are significantly large to indicate that the amount of gaseous $\mathrm{CO}_{2}$ or even ethanol released from the system is larger.

As noted earlier, WF contains about $73 \%$ starch, $14 \%$ protein and other minor ingredients ${ }^{17}$. Thus, the observed higher rate of weight loss corresponds to the faster decomposition of protein and other ingredients. In fact, the faster rate of decomposition of WF results in faster recovery of $\mathrm{MB}$ from MB-WF residue (compare A and B in Fig. 5). The observed higher \% recovery of $\mathrm{MB}$ in the presence of yeast at $37{ }^{\circ} \mathrm{C}$ may also be understood. In the presence of yeast, the biodegradation reaction (fermentation reaction shown in Eq. 7) would take place catalytically since $37^{\circ} \mathrm{C}$ is favorable for optimum activity of yeast ${ }^{17}$. To confirm the formation of ethanol in the solution, the synthetic waste was allowed to undergo fermentation reaction. The products generated were analyzed by chemical means, UV-visible spectroscopy and GC analysis. Ceric ammonium nitrate solution was added to an aliquot of the sample and a formation of red color for alkoxy cerium(IV) compound was noticed indicating the presence of alcohol (Eq. 8) ${ }^{27}$.

$\mathrm{ROH}+\left(\mathrm{NH}_{4}\right)_{2} \mathrm{Ce}\left(\mathrm{NO}_{3}\right)_{6} \rightarrow\left(\mathrm{NH}_{4}\right)_{2} \mathrm{Ce}-\mathrm{OR}\left(\mathrm{NO}_{3}\right)_{6}+\mathrm{HNO}_{3}$

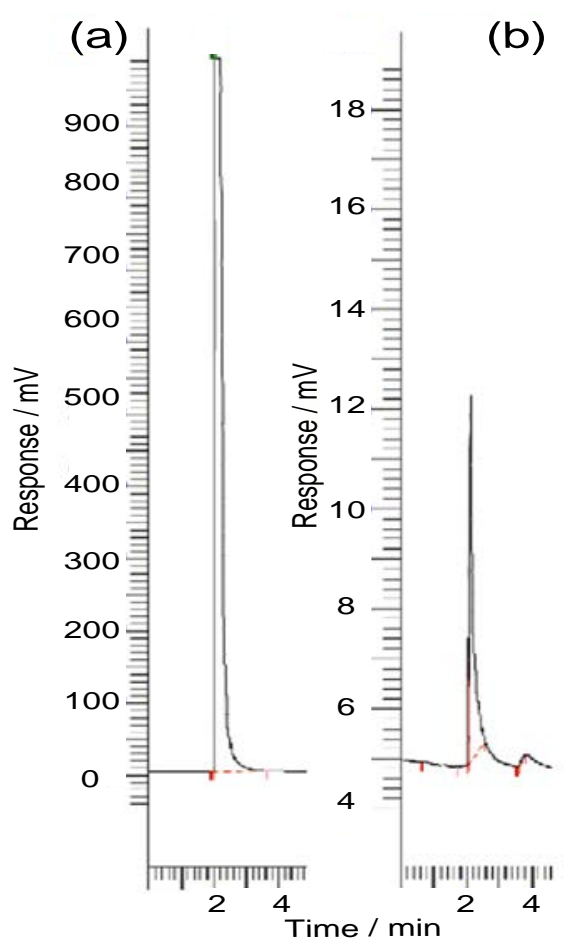

Fig. 6. Chromatograms recorded for (a) pure ethanol and (b) the product obtained by fermentation of the adsorbent from MB-WF species.
The sample was also subjected to a fractional distillation and the product was identified as ethanol by GC (Fig. 6). The residue was blue in color and after distillation it was dissolved in water and a visible spectrum was recorded for the clear solution. The UV-visible spectrum (not shown) was similar to that shown in Fig. 3.

The mechanism of desorption of MB from the surface of starch may be schematically represented in Scheme 1. Since the adsorption is an equilibrium process, a portion of $\mathrm{MB}$ desorbs as soon as the MB-WF and MB-starch species are charged into water. Such desorption of MB allows the microorganism present in the system to come closer to the surface of starch particles. The microorganisms are thus encapsulated to the surface of starch or WF particles and simultaneously MB species desorbs back to the solution. The surface-bound microorganisms restrict further adsorption of $\mathrm{MB}$ species. Desorption of $\mathrm{MB}$ results from natural decomposition of the surface of starch/WF particle, whereas MB species does not undergo degradation as reported for other dyes in the presence of fungi and bacteria ${ }^{26}$. However, the fermentation reaction in the presence of yeast ultimately results in a faster recovery of $\mathrm{MB}$ as well as conversion of starch into alcohol. MB dye can, therefore, be successfully recovered from MB-WF and MB-starch residue by conversion of starch of into alcohol. It is clear that the starch material could be converted into ethanol by the action of yeast without degradation of the dyestuff adsorbed on it.

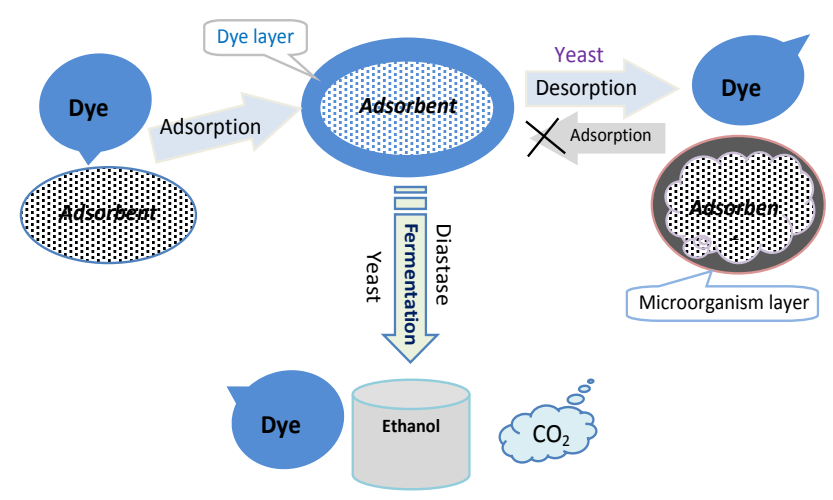

Scheme.1. Possible routes of adsorption and recovery of MB from MB-starch species.

\section{Conclusions}

The recovery of $\mathrm{MB}$ adsorbed on WF and starch was successfully carried out through desorption of MB. The rate of desorption was enhanced by increasing temperature and addition of yeast. The maximum recovery of $\mathrm{MB}$ at $37{ }^{\circ} \mathrm{C}$ in the presence of yeast was more than $99 \%$ within the time of less than $10 \mathrm{~h}$. The starch material was converted into ethanol by the action of yeast without degradation of the dyestuff. The desorption of MB is predicted to result from natural decomposition of adsorbents due to the action of microorganism present in water and the fermentation of the adsorbent catalyzed by added yeast. These results thus offer a potential for development of a low-cost, environmentally friendly and sustainable methodology for treatment of industrial effluent containing MB or any other organic dye. 


\section{Acknowledgement}

The authors gratefully acknowledge the support of University Grants Commission of Bangladesh for funding through University of Dhaka. The authors also gratefully acknowledge financial support for a sub-project (CP-231) from the Higher Education Quality Enhancement Project (HEQEP) of the University Grants Commission of Bangladesh financed by the World Bank and the Government of Bangladesh.

\section{References}

1 Robinson, T., G. McMullan, R. Marchant and P. Nigam, 2001. Remediation of Dyes in Textile Effluent: A Critical Review on Current Treatment Technologies with a Proposed Alternative, Bio. Tech., 77, 247-55.

2 Ayad, M. M. and A. A. El-Nasr, 2010. Adsorption of Cationic Dye (Methylene Blue) from Water using Polyaniline Nanotube Base, J. Phys. Chem. C, 114, 14377-14383.

3 Farhana, T. I., M. Y. A. Mollah, M. A. B. H. Susan and M. M. Islam, 2014. Catalytic Degradation of an Organic Dye through Electroreduction of Dioxygen in Aqueous Solution, Electrochim. Acta, 139, 244-249.

4 Rodrigues, C. S. D., L. M. Madeira and R. A. R. Boaventura, 2009. Treatment of Textile Effluent by Chemical (Fenton's Reagent) and Biological (Sequencing Batch Reactor) Oxidation, J. Hazard. Mater., 172, 1551-1559.

5 Banat, I. M., P. Nigam, P. D. Singh and R. Marchant, 1996. Microbial Decolorization of Textile-Dye Containing Effluents: A Review, J. Bioresour. Technol., 58, 217- 227.

6 Blackburn, R. S., 2004. Natural Polysaccharides and their Interactions with Dye Molecules: Applications in Effluent Treatment, Environ. Sci. Technol., 38, 4905-4909.

7 Ali, I., 2012. New Generation Adsorbents for Water Treatment, Chem. Rev., 112, 5073-5091.

8 Mezohegyi, G., F. P. V. D. Zee, J. Font, A. Fortuny and A. Fabregat, 2012. Towards Advanced Aqueous Dye Removal Processes: A Short Review on the Versatile Role of Activated Carbon, J. Environ. Manage., 102, 148-164.

9 Chowdhury, A.-N., S. R. Jesmeen and M. M. Hossain, 2004. Removal of Dyes from Water by Conducting Polymeric Adsorbent, Polym. Adv. Technol., 15, 633-638.

10. Nigam, P., G. Armour, I. M. Banat, D. Singh and R. Marchant, 2000. Physical Removal of Textile Dyes from Effluents and Solid-State Fermentation of Dye-Adsorbed Agricultural Residues, Bioresour. Technol., 72, 219-226.

11. Robinson, T., B. Chandran and P. Nigam, 2002. Studies on Desorption of Individual Textile Dyes and a Synthetic Dye Effluent from Dye-Adsorbed Agricultural Residues Using Solvents, Bio. Tech., 84, 299-301.

12. Zhou, Q. and M. Wang, 2010. Adsorption-Desorption Characteristics and Pollution Behavior of Reactive X-3B Red Dye in Four Chinese Typical Soils, J. Soils Sediments, 10, 1324-1334.
13. Zargar, B., H. Parhan and M. Rezazade, 2011. Fast Removal and Recovery of Methylene Blue by Activated Carbon Modified with Magnetic Iron Oxide Nanoparticles, J. Chin. Chem. Soc., 58, 694-699.

14. Zheng, L., S. Yanlei, L. Wang and Z. Jiang, 2009. Adsorption and Recovery of Methylene Blue from Aqueous Solution through Ultrafiltration Technique, Sep. Purif. Technol., 68, 244-249.

15. Muthuraman, G., T. T. Teng, C. P. Leh and I. Norli, 2009. Extraction and Recovery of Methylene Blue from Industrial Wastewater Using Benzoic Acid as an Extractant, J. Hazard Mater., 163, 363-369.

16. Yeamin, M. B., 2009. Preparation of Nano-Materials and Their Recyclable Application in the Removal of Organic Dyes from Aqueous Solution, M. Phil. Thesis, Bangladesh University of Engineering and Technology, Dhaka, Bangladesh.

17. Neves, M. A., T. Kimura, N. Shimizu and K. Shiiba, 2006. Production of Alcohol by Simultaneous Saccharification and Fermentation of Low-Grade Wheat Flour, Braz. Arch. Biol. Technol., 49, 481-490.

18. Cheng, R., O. Shengju, L. Mengjie, L. Yijiu and B. Xiang, 2009. Ethylenediamine Modified Starch as Biosorbent for Acid Dyes, J. Hazard. Mater., 172, 1665-1670.

19. Vikman, M., M. Itiivaara and K. Poutanen, 1995. Measurement of the Biodegradation of Starch-Based Materials by Enzymatic Methods and Composting, $J$. Environ. Poly. Deg., 3, 23-29.

20. Primarini, D. and Y. Ohta, 2000. Some Enzyme Properties of Raw Starch Digesting Amylases from Streptomyces, Starch, 52, 28-32.

21. Öner, E. T., S. G. Oliver and B. Kirdar, 2005. Production of Ethanol from Starch by Respiration- Deficient Recombinant Saccharomyces cerevisiae, Appl. Environ. Microbiol., 71, 6443-6445.

22. Banerjee, M., S. Debnath and S. K. Majumdar, 1988. Production of Alcohol from Starch by Direct Fermentation, Biotechnol. Bioeng, 32, 831-834.

23. Alonso, S., M. Arevalo-Villena and A. B. Ubeda, 2010. Study of Starch Degradation by Yeasts during Fermentation for Using in Animal Feed, Appl. Biochem. Biotechnol., 162, 2058-2066.

24. Nakamura, Y., F. Kobayashi, M. Ohnaga and T. Sawada, 1997. Alcohol Fermentation of Starch by a Genetic Recombinant Yeast having Glucoamylage Activity, Biotechnol. Bioeng., 53, 21-25.

25. Austin, G. T., 2008. Shreve's Chemical Process Industries, $5^{\text {th }}$ ed., McGraw-Hill, New Delhi.

26. Ali, H., 2010. Biodegradation of Synthetic Dyes, Water Air Soil Pollut., 213, 251-273.

27. Doyle, M. P., 1974. A Spectrometric Study of the Oxidation of Alcohols by Cerium (IV), J. Chem. Educ., 51, 131-132. 
Dhaka Univ. J. Sci. 63(2): 119-124, 2015 (July)

* Author for correspondence. e-mail:mominul@du.ac.bd 